\title{
Heat transfer investigations in a liquid that is mixed by means of a multi- ribbon mixer
}

\author{
Tomasz Borowski, Dawid Sołoducha, Daniel Musik, Krzysztof Wójcik, Mariusz Chyla, Katarzyna \\ Ziętarska, Małgorzata Friedrich, Anna Kiełbus-Rapała, Marian Kordas, Maciej Konopacki, \\ Rafał Rakoczy*
}

\author{
West Pomeranian University of Technology in Szczecin, Faculty of Chemical Technology and Engineering, 42 Piastów, \\ 71-065 Szczecin, Poland \\ "Corresponding author: e-mail: rrakoczy@zut.edu.pl
}

\begin{abstract}
The objective of this paper is to present the investigations of the heat transfer process carried out by means of the multi-ribbon mixer. It is shown that the heat transfer process for the synergic effect of the mixing process and the flowing liquid through the mixer has significantly higher values of the heat transfer coefficients than the mixer with motionless impellers. The empirical correlations between the heat transfer coefficient and the operational parameters obtained in this work can provide guidance for the design and operation of an apparatus equipped with the multi-ribbon impeller. These empirical correlations can be used to predict the heat transfer coefficient for the multi-ribbon mixer.
\end{abstract}

Keywords: multi-ribbon impeller, heat transfer process, heat transfer coefficient, correlation.

\section{INTRODUCTION}

Owing to their importance in the field of many industrial applications such as manufacturing of chemicals, drugs, and food, mixing operation of liquid have been the subject of many investigations. The mixing process of viscosity or non-Newtonian liquids is often carried out by using the mixer equipped with the Rushton turbine ${ }^{1}$ or in the hybrid mixing system composed of the helical ribbon and the Rushton turbine ${ }^{2}$. The relevant reports have been focused on the studies of the application of helical ribbon agitator ${ }^{3-10}$ as well on the numerical analysis $^{11-12}$

A growing interest in the investigation of the effect of ribbon mixer on the heat transfer process has been noticed in the ${ }^{13-18}$. Delaplace et al. ${ }^{19}$ analyzed the data of the heat transfer process in the atypical helical ribbon impeller supported by two vertical arms and concluded that the heat flux sensors can monitor the thermal boundary layer thickness. It should be noticed that the rate of heat transfer from the vessel wall to the mixing liquid is dependent on the thickness of the thermal boundary layer $^{20}$. These authors reported a new and convenient synthetic procedure to obtain the heat transfer efficiency for ribbon impellers operating in a laminar regime. Nzihou et al. ${ }^{21}$ studied the effects of a rheo-reactor (the vessel with a helical-ribbon impeller) on the heat transfer coefficient. One study by Delaplace et al. ${ }^{22}$ examined the heat transfer for a jacketed vessel fitted with an atypical helical ribbon. In this work, numerical simulations of heat transfer phenomena to highly viscous Newtonian at unsteady states in this mixer were also attempted using CFD finite volume software. Rai et al. ${ }^{23}$ found that the flat-bottomed vessel equipped with a helical ribbon agitator can be applied for the heat transfer enhancement for some Newtonian and non-Newtonian fluids. As noted by these authors the heat transfer coefficient did not increase substantially when aeration was coupled with agitation as compared to the only aeration. Saraceno et al..$^{24}$ discuss the heat transfer efficiency in the mixing system equipped with an agitator type helical ribbon. Gammoudi et al. ${ }^{25}$ analyzed the hydrodynamic and thermal behaviors of yield stress fluids within the vessel equipped with simple helical ribbon stirrers by using the numerical simulation approach.

It may be noted that there is a lack of systematic studies with the heat transfer studies in the multi-ribbon mixer. Previous research has indicated that the heat transfer coefficient at the wall of the agitated vessel depended on many factors, such as the type and geometry of the vessel and agitator ${ }^{26}$. To obtain an accurate correlation of heat transfer coefficient and to predict the heat transfer efficiency in the mixed liquid, it is necessary to clarify the relation between heat transfer and fluid flow in the mixer. Therefore, in the present study, some analyses on the heat transfer performance of the multi-ribbon mixer are presented. This study aims to investigate the heat transfer process in the multi-ribbon mixer for a Newtonian fluid. It should be noticed that the two cases were considered: i) multi-ribbon mixer with motionless impellers acting as a heat exchanger (tap water as the working liquid flowed through the mixer); ii) multi-ribbon mixer with working impellers and fluid flow through the mixer (the effect of mixing process on heat transfer when the water flowed through the mixer). Due to practical constraints, this paper cannot provide comprehensive experimental work with the highly viscous Newtonian and non-Newtonian fluid. Therefore, the obtained results may be treated as preliminary research which can be the basis for further work with the usage of the multi-ribbon mixer to intensify the heat transfer process.

\section{Theoretical}

The mathematical description of heat transfer operations may be defined by using the governing equation of the temperature field (the Fourier-Kirchhoff equation) $)^{27}$. This equation for $p=$ const and $\Phi_{V}=0$ (where $p$ is pressure and $\Phi_{V}$ is viscous dissipation function) is given as follows

$\frac{\partial T}{\partial \tau}+\boldsymbol{w} \operatorname{grad} T=\operatorname{div}\left(\frac{\lambda}{\rho c_{p}} \operatorname{grad} T\right)$ 
where:

$c_{p}$ - specific heat, $\mathrm{J} \cdot \mathrm{kg}^{-1} \cdot \mathrm{K}^{-1}$;

$T$ - temperature, $\mathrm{K}$;

$\boldsymbol{w}$ - velocity vector, $\mathrm{m} \cdot \mathrm{s}^{-1}$;

Q - liquid density, $\mathrm{kg} \cdot \mathrm{m}^{-3}$;

$\lambda \quad$ - thermal conductivity, $\mathrm{J} \cdot \mathrm{m}^{-1} \cdot \mathrm{K}^{-1} \cdot \mathrm{s}^{-1}$;

$\tau$ - time, $s$.

Equation (1) may be rewritten in the symbolic form which is useful for the dimensional analysis. The introduction of non-dimensional quantities denoted by an asterisk $(*)$ into this relationship yields

$\left.\frac{\rho c_{p} T}{\tau}\left[\rho^{*} c_{p}{ }^{*} \frac{\partial T^{*}}{\partial \tau^{*}}\right]\right\rfloor+\frac{\rho c_{p} w T}{l}\left[\rho^{*} c_{p}{ }^{*} w^{*} \operatorname{grad}^{*} T^{*}\right]=$

$=\frac{\lambda T}{l^{2}}\left[\operatorname{div}^{*}\left(\lambda^{*} \operatorname{grad}^{*} T^{*}\right)\right]$

The non-dimensional form of Eq. (2) may be scaled against the convective term $\left(\lambda T l^{-2}\right)$. The result of this operation is given as follows

$\frac{\rho c_{p} l^{2}}{\lambda \tau}\left[\dot{\rho}^{*} c_{p}{ }^{*} \frac{\partial T^{*}}{\partial \tau^{*}}\right]+\frac{\rho c_{p} w l}{\lambda}\left[\rho^{*} c_{p}^{*} w^{*} \operatorname{grad}^{*} T^{*}\right]=$

$=\left[\operatorname{div}^{*}\left(\lambda^{*} \operatorname{grad}^{*} T^{*}\right)\right]$

Considering the following non-dimensional groups

$\mathrm{Fo}=\frac{\lambda \tau}{\rho c_{p} l^{2}} \Rightarrow \mathrm{Fo}=\frac{a \tau}{l^{2}}$

$\mathrm{Pe}=\frac{\rho c_{p} w l}{\lambda} \Rightarrow \mathrm{Pe}=\frac{w l}{a}$

we obtain the following relation

$\mathrm{Fo}^{-1}\left[\rho^{*} c_{p}{ }^{*} \frac{\partial T^{*}}{\partial \tau^{*}}\right]+\operatorname{Pe}\left[\rho^{*} c_{p}{ }^{*} w^{*} \operatorname{grad}^{*} T^{*}\right]=$

$=\left[\operatorname{div}^{*}\left(\lambda^{*} \operatorname{grad}^{*} T^{*}\right)\right]$

where:

$a$ - thermal diffusivity, $\mathrm{m}^{2} \cdot \mathrm{s}$;

$l$ - characteristic length, $\mathrm{m}$;

Fo - dimensionless Fourier number;

$\mathrm{Pe}-$ dimensionless Péclet number.

The heat transfer process between the wall and the fluid can be described by means of the following relationship

$\alpha=-\frac{\lambda(\nabla T)_{w}}{\operatorname{dif}(T)} \Rightarrow \alpha=-\frac{\lambda(\nabla T)_{w}}{T_{w}-T_{f}}$

where:

$T_{f}$ - temperature of fluid, $\mathrm{K}$;

$T_{w}$ - temperature of wall, $\mathrm{K}$;

$\alpha$ - heat transfer coefficient, $\mathrm{J} \cdot \mathrm{m}^{-2} \cdot \mathrm{K}^{-1} \cdot \mathrm{s}^{-1}$.

The Eq. (7) may be also expressed in the following non-dimensional form

$\alpha\left[\alpha^{*}\right]=\frac{\lambda T}{l T}\left[\left.\frac{\lambda^{*}\left(\nabla^{*} T^{*}\right)}{(\operatorname{dif}(T))^{*}}\right|_{\rfloor}\right.$

The consequence of this operation is that the heat transfer process may be characterized by using the dimensionless Nusselt number $\frac{\alpha l}{\lambda}=1 \Rightarrow \mathrm{Nu}=\frac{\alpha l}{\lambda}$

From the above equations, it follows that the heat transfer process for the steady conditions may be defined by using the equation

$\mathrm{Nu}=f(\mathrm{Pe})$

It should be noticed that the dimensionless Péclet number may be expressed as follows

$\mathrm{Pe}=\frac{w l}{a} \Rightarrow \mathrm{Pe}=\left(\frac{w l}{v}\right)\left(\frac{c_{p} \eta}{\lambda}\right) \Rightarrow \mathrm{Pe}=\operatorname{Re} \operatorname{Pr}$

where:

Pr - dimensionless Prandtl number;

$\mathrm{Re}$ - dimensionless Reynolds number;

$\eta$ - dynamic viscosity, $\mathrm{kg} \cdot \mathrm{m}^{-1} \cdot \mathrm{s}^{-1}$;

$v$ - kinematic viscosity, $\mathrm{m}^{2} \cdot \mathrm{s}^{-1}$.

In the case of the application of the experimental methods, the heat transfer coefficient is correlated by means of the following equation ${ }^{20}$

$\mathrm{Nu}=C \operatorname{Re}^{a} \operatorname{Pr}^{0.33} \mathrm{Vi}^{0.14}$

where:

a, $C$ - parameters;

$\mathrm{Vi}$ - viscosity simplex defined as the ratio dynamic viscosity of the fluid and the dynamic viscosity of the fluid at the wall temperature.

\section{EXPERIMENTAL}

\section{Experimental set-up}

Experimental investigations were carried out using the set-up with the multi-ribbon mixer shown schematically in Fig. 1.

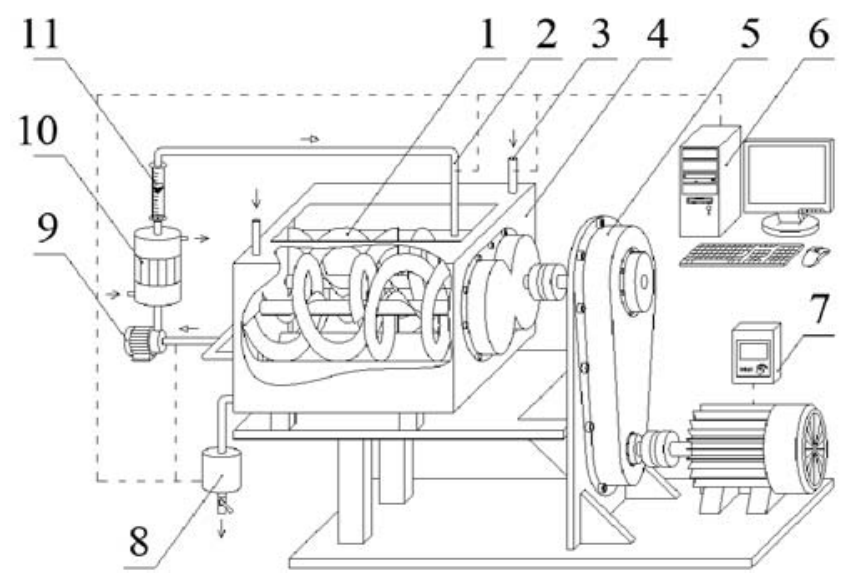

Figure 1. Experimental set-up: 1 - impeller, 2 - water inlet, 3 - steam inlet, 4 - heating jacket, 5 - gear transmission, 6 - computer, 7 - inverter, 8 - condenser pot, 9 - pump, 10 - heat exchanger, 11 - rotameter

The mixer is constructed in the form of two partly penetrating horizontal stainless steel cylinders. The main geometrical parameters of the mixer are as follows: diameter of each cylinder: $0.186 \mathrm{~m}$, length of the cylinder: 0.34 $\mathrm{m}$, total volume: $0.025 \mathrm{~m}^{3}$. The tested mixer is equipped with the jacket and adequate piping for the delivery of the heating medium (water steam) into the jacket of the mixer. The heating jacket was supplied with stabilized 
steam at a pressure of $0.11 \mathrm{MPa}$ and temperature approximately $102^{\circ} \mathrm{C}$. A manometer and thermometer were used to control these operational parameters.

The mixing process was performed using two co-operating helical multi-ribbon impellers. In the case of this experimental work, we tested three geometrical configurations of impellers (see Fig. 2).

The geometrical parameters of the tested impellers are collected in Table 1.

\section{Experimental procedure}

In the present investigations, the averaged heat transfer coefficient from the heating jacket to the liquid was measured by the stabilized heat flow method. All experiments were carried out for the steady-state conditions, in which heat supplied to the tank from steam condensing in the jacket was received by the circulating liquid. A detailed description of the measurement of heat transfer coefficients on the tank wall was presented by Niedzielska and Kuncewicz ${ }^{\mathbf{2 0}}$. It should be noticed that the heat passing into the vessel through the wall and the heat absorbed by the mixed liquid are essentially equal.

The heat transfer rate exchanged between the heating medium (condensing steam) and the mixed liquid (water; the inlet temperature of this liquid was about $5^{\circ} \mathrm{C}$ ) flowing through the mixer is defined by the following equation

$\dot{Q}=\dot{G}_{w} c_{p}\left(T_{\text {out }}-T_{\text {in }}\right)$

where:

$\dot{G}_{w}-$ mass flow rate, $\mathrm{kg} \cdot \mathrm{s}^{-1}$;

$c_{p} \quad-$ mixing liquid specific heat, $\mathrm{J} \cdot \mathrm{kg}^{-1} \cdot \mathrm{deg}^{-1}$;

$T_{i n}$ - temperature of the liquid at the mixer inlet, ${ }^{\circ} \mathrm{C}$;

$T_{\text {out }}$ - temperature of the liquid at the mixer outlet, ${ }^{\circ} \mathrm{C}$;

$\dot{Q}$ - heat transfer rate, $\mathrm{J} \cdot \mathrm{s}^{-1}$.

The heat transfer coefficient from heating wall to mixed liquid is described by the following relation

$\alpha=\frac{\dot{Q}}{F_{H T}\left(T_{w}-T_{b u l k}\right)}$

where:

$F_{H T}$ - heat transfer area, $\mathrm{m}^{2}$;

$T_{w} \quad$ - temperature of the vessel wall, ${ }^{\circ} \mathrm{C}$;
$T_{\text {bulk }}$ - temperature of the mixed liquid, ${ }^{\circ} \mathrm{C}$;

$\alpha \quad-$ heat transfer coefficient, $\mathrm{J} \cdot \mathrm{m}^{-2} \cdot \mathrm{K}^{-1} \cdot \mathrm{s}^{-1}$.

In the case of this experimental work, the temperatures were measured with thermal sensors (Pt100A) and

a)

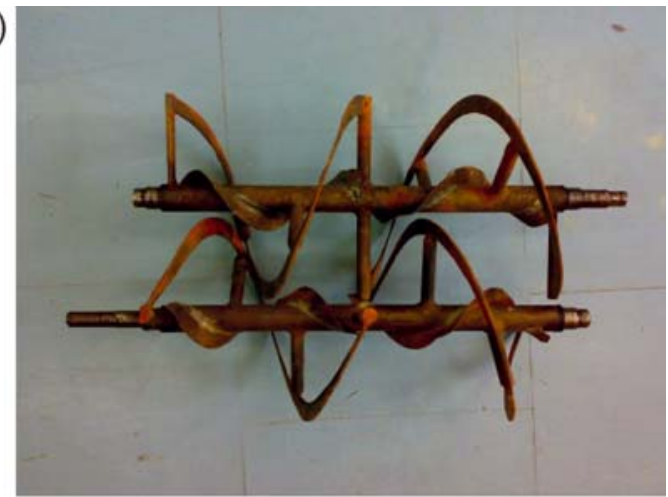

b)

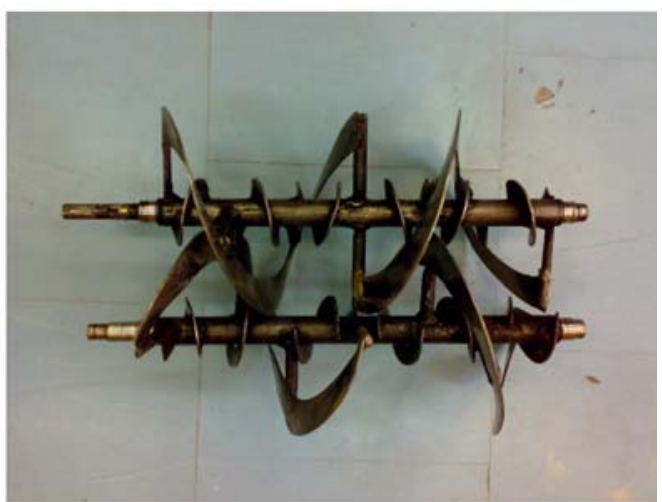

c)

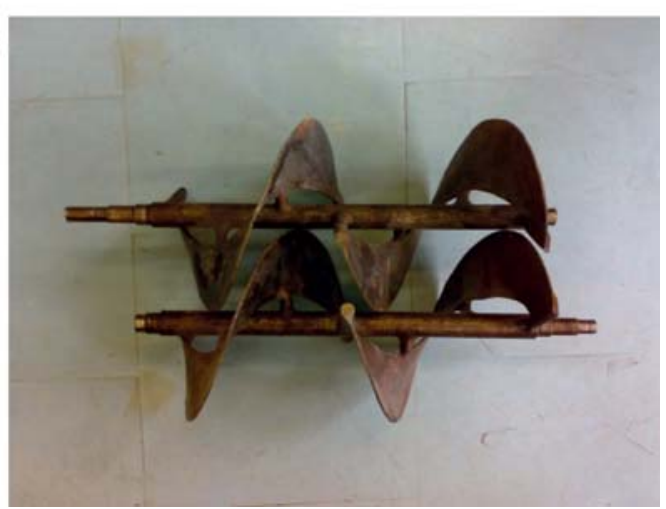

Figure 2. The views of the tested two co-operating helical multi-ribbon impellers

Table 1. The list of the geometrical parameters of the tested impellers

\begin{tabular}{|c|c|c|c|}
\hline \multirow{2}{*}{ Parameter } & \multicolumn{3}{|c|}{ Tested impellers } \\
\hline & A 1 (Fig. 2a) & A 2 (Fig. 2b) & A 3 (Fig. 2c) \\
\hline Material of construction & alloy steel & stainless steel & alloy steel \\
\hline Number of ribbons & 2 & 2 & 2 \\
\hline $\begin{array}{c}\text { Diameter/length of the } \\
\text { shaft [mm] }\end{array}$ & $24 / 350$ & $24 / 350$ & $24 / 350$ \\
\hline $\begin{array}{l}\text { Ribbon } \\
\text { length/thickness of } \\
\text { ribbon impeller [mm] }\end{array}$ & $590 / 2$ & $580 / 2$ & $600 / 2$ \\
\hline Width of ribbons [mm] & 15 & 30 & 60 \\
\hline $\begin{array}{l}\text { Distance between the } \\
\text { axis of impellers [mm] }\end{array}$ & 60 & 45 & 30 \\
\hline Additional ribbons & $\begin{array}{l}\text { On the shaft: two ribbons made of the thin metal } \\
\text { sheet placed along the entire length of the shaft } \\
\text { (20mm wide and } 300 \mathrm{~mm} \text { long). }\end{array}$ & $\begin{array}{c}\text { On the shaft: } 6 \text { ribbons placed } \\
\text { directly on the shaft (length } 195 \mathrm{~mm} \\
\text { and width } 20 \mathrm{~mm} \text { ). }\end{array}$ & $\begin{array}{l}\text { No additional } \\
\text { ribbons. }\end{array}$ \\
\hline
\end{tabular}


a measuring instrument that controlled the temperature of the set-up and supervised the real-time acquisition of all experimental data coming from the sensors. According to PN-EN 60751:1997+A2, the temperature measurement errors with this sensor at $5^{\circ} \mathrm{C}$ and $100^{\circ} \mathrm{C}$ are equal to $0.17^{\circ} \mathrm{C}$ and $0.35^{\circ} \mathrm{C}$, respectively. The location of temperature sensors is shown in Fig. 3.

It should be noticed that the temperature of the vessel wall $T_{w}$ was calculated as the average of temperatures from $T_{1}$ to $T_{5}$.
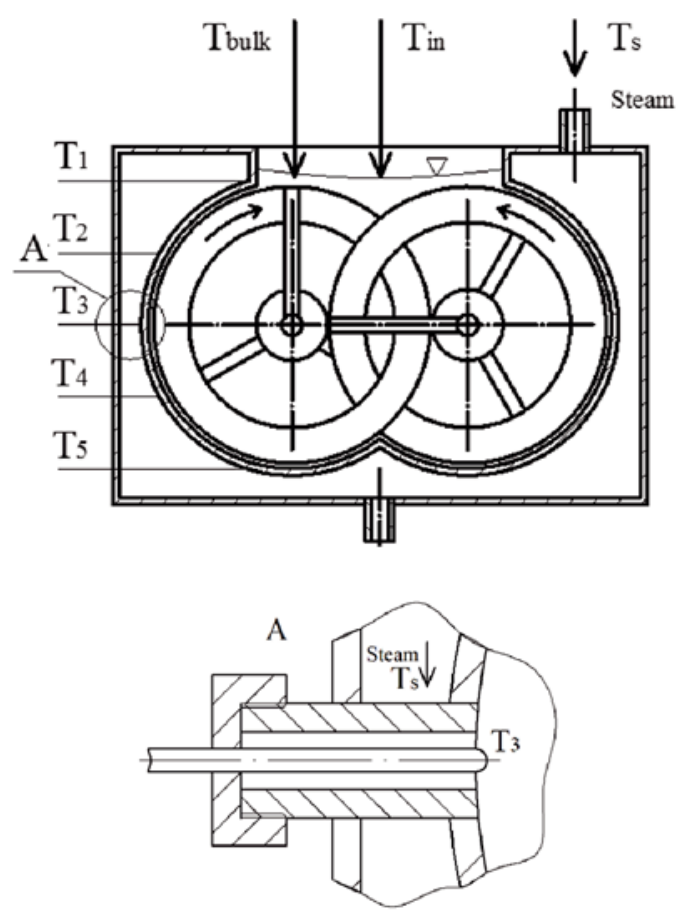

Figure 3. The localization of temperature sensors in the tested mixer

\section{Calculation of dimensionless numbers}

The investigations were carried out for two cases. Firstly, the influence of the motionless impellers (see Fig. 2) on the heat transfer process was analyzed. In this case, the tested vessel equipped with the multi-ribbon impeller may be treated as the heat exchanger. Secondly, the effect of various types of impellers on heat transfer performance was discussed.

In the first case, the heat transfer process may be conveniently correlated using the following relation

$\frac{\mathrm{Nu}}{\operatorname{Pr}^{0.33} \mathrm{Vi}^{0.14}}=f\left(\operatorname{Re}_{\text {flow }}\right) \Rightarrow \frac{\left(\frac{\alpha D_{\text {mixer }}}{\lambda}\right)}{\left(\frac{c_{p} \eta}{\lambda}\right)^{0.33}\left(\frac{\eta}{\eta_{w}}\right)^{0.14}}=$

$=f\left(\frac{w_{\text {flow }} D_{\text {mixer }}}{v}\right)$

where:

$D_{\text {mixer }}$ - diameter of the mixer, m;

$w_{\text {flow }}-$ liquid velocity flowing through the mixer, $\mathrm{m} \cdot \mathrm{s}^{-1}$;

$\eta \quad-$ dynamic viscosity of the fluid at mixing temperature, $\mathrm{kg} \cdot \mathrm{m}^{-1} \cdot \mathrm{s}^{-1}$; $\eta_{w} \quad$-dynamic viscosity of the fluid at wall temperature, $\mathrm{kg} \cdot \mathrm{m}^{-1} \cdot \mathrm{s}^{-1}$;

$\lambda \quad-$ thermal conductivity of liquid, $\mathrm{W} \cdot \mathrm{m}^{-1} \cdot \mathrm{deg}^{-1}$;

$v \quad-$ kinematic viscosity of the fluid at mixing temperature, $\mathrm{m}^{2} \cdot \mathrm{s}^{-1}$.

The liquid velocity flowing through the mixer is defined as follows

$w_{\text {flow }}=\frac{\dot{G}_{w}}{F_{\text {flow }} \rho} \Rightarrow w_{\text {flow }}=\frac{4}{\pi} \frac{\dot{G}_{w}}{\left(D_{\text {mixer }}\right)^{2} \rho}$

where:

$F_{\text {flow }}$ - cross-sectional area of the mixer, $\mathrm{m}^{2}$;

@ - density of the liquid, $\mathrm{kg} \cdot \mathrm{m}^{-3}$.

The diameter of the mixer, $D_{\text {mixer }}$, was equal to $0.26 \mathrm{~m}$. This is equivalent diameter calculated as follows

$D_{\text {mixer }}=\sqrt{\frac{4 F_{m}}{\pi}} \Rightarrow D_{\text {mixer }}=\sqrt{\frac{8 F_{c}}{\pi}} \Rightarrow D_{\text {mixer }}=\sqrt{2 D^{2}}$

where:

$F_{m} \quad$ - cross-sectional area of the mixer which is composed - of two cylinders, $\mathrm{m}^{2}$;

$F_{c} \quad$ - cross-sectional area of the mixer cylinder, $\mathrm{m}^{2}$;

$D$ - diameter of cylinder, $\mathrm{m}$.

The mass flow ratio of water was varied between 0.0278 and $0.2222 \mathrm{~kg} \cdot \mathrm{s}^{-1}$. The liquid velocity $w_{\text {flow }}$ was changed between 0.00052 and $0.0042 \mathrm{~m} \cdot \mathrm{s}^{-1}$. The dimensionless Prandtl number and the viscosity simplex were changed in the range between 4.54-13.41 and 1.02-5.24, respectively.

The generalization of the effect of mixing on the heat transfer when fluid flows through the vessel is given in the following form

$\frac{\mathrm{Nu}}{\operatorname{Pr}^{0.33} \mathrm{Vi}^{0.14}}=f\left(\operatorname{Re}_{f l o w}, \operatorname{Re}_{\text {mix }}\right) \Rightarrow \frac{\left(\frac{\alpha D_{\text {mixer }}}{\lambda}\right)}{\left(\frac{c_{p} \eta}{\lambda}\right)^{0.33}\left(\frac{\eta}{\eta_{w}}\right)^{0.14}}=$

$=f\left(\frac{w_{\text {flow }} D_{\text {mixer }}}{v}, \frac{N\left(d_{\text {mix }}\right)^{2}}{v}\right)$

where:

$N \quad$ - rotational speed of impeller, $\mathrm{s}^{-1}$;

$d_{m i x}$ - diameter of impeller, $\mathrm{m}$.

The rotational speed of impeller was varied from 20 rpm to $104 \mathrm{rpm}$.

\section{RESULTS AND DISCUSSION}

In the case of this experimental work, the enhancement of the heat transfer process was realized by applying the tested multi-ribbon mixer with impellers (see Fig. 2). As it was mentioned above, the influence of motionless impellers on this process was discussed. In this case, the tested mixer may be treated as the heat exchanger.

In the present report, we consider that the heat transfer in the multi-ribbon mixer acted as the heat exchanger may be described by the proposed relationship between the dimensionless Nusselt number and the dimensionless Reynolds number for the fluid flow through the mixer (Eq. (15)). To establish the effect of the hydrodynamic conditions on the heat transfer process, the experimental 
data obtained in this work are graphically illustrated in the log-log system in Fig. 4.

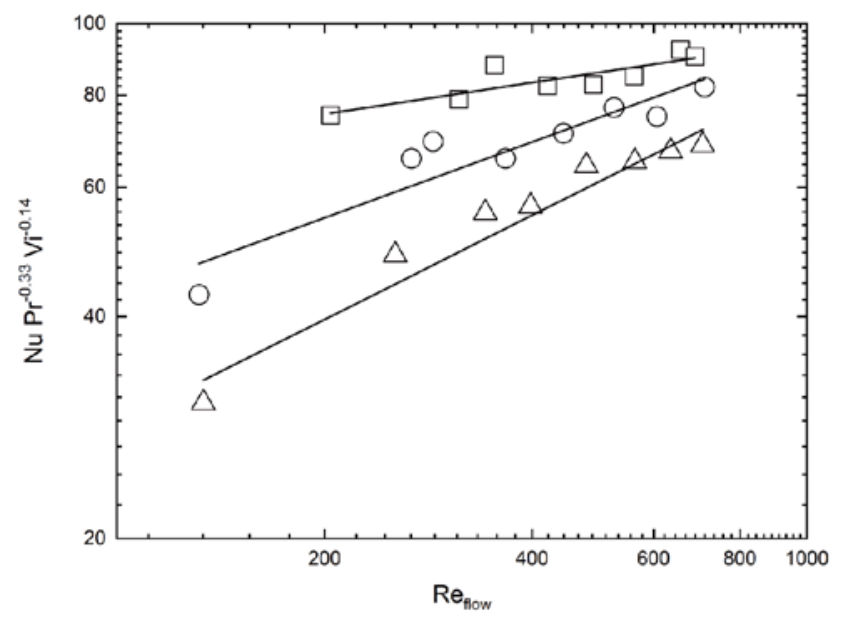

Figure 4. The generalization of the results of the heat transfer measurements for impeller A_1 (see Fig. 2a; symbol $\square$ ), impeller A_2 (see Fig. 2a; symbol $\bigcirc$ ), and impeller A_3 2 (see Fig. 2a; symbol $\Delta$ )

The experimental results shown in Fig. 4 suggest that the heat transfer process may be analytically described by the following function (based on Eq. (15))

$$
\frac{\mathrm{Nu}}{\operatorname{Pr}^{0.33} \mathrm{Vi}^{0.14}}=p_{1}\left(\operatorname{Re}_{\text {flow }}\right)^{p_{2}}
$$

The constants and exponents were computed by means of the Matlab software and the principle of least squares and the obtained values are collected in Table 2 .

It can be seen from Fig. 4 that the experimental points for the various impellers may be described by the same type of relation (Eq. (19)) using the various values of the parameters $p_{1}$ and $p_{2}$. It is clear that the heat transfer process is dependent on the geometrical configuration of the multi-ribbon impeller that acted as the motion- less insert in the mixer. The enhancement of the heat transfer process can be attributed to the breakdown of the thermal boundary layer especially near the wall of the mixer. It should be noticed that the enhancement of heat transfer is provided by the mixer in which the clearance between the ribbons is larger. This leads to an increase in the turbulence in the flowing liquid. Thus, the improvement of the heat transfer ratio may be obtained.

To establish the effect of the tested mixing system and the applied hydrodynamic conditions connected with the flowing fluid through the mixer, the experimental data obtained in this work are described by the following correlation

$\frac{\mathrm{Nu}}{\operatorname{Pr}^{0.33} \mathrm{Vi}^{0.14}}=p_{3}\left(\operatorname{Re}_{\text {flow }}\right)^{p_{4}}\left(\operatorname{Re}_{\text {mix }}\right)^{p_{5}}$

The constants and exponents of Eq. (20) for the tested impellers are collected in Table 3.

The applied mixing system has a significant effect on the heat transfer coefficient expressed in the form of the term $\mathrm{Nu} \mathrm{Pr}^{-0.33} \mathrm{Vi}^{-0.14}$. An increase in the dimensionless Reynolds number for the mixing system, $\mathrm{Re}_{\text {mix }}$, increased the values of the mentioned term. This trend can be better observed from the plot shown in Fig. 5 .

Table 4 presents some of the main heat transfer effects associated with the application of the tested mixing systems in the multi-ribbon mixer.

The current study found that the application of the tested multi-ribbon impeller and the mixing system has a significant effect on the heat transfer ratio. Figure 5 shows that the values of this coefficient for the tested mixer increase with $\operatorname{Re}_{m i x}$. In the case of impeller A_1 the values of term $\mathrm{Nu} \operatorname{Pr}^{-0.33} \mathrm{Vi}^{-0.14}$ decrease with $\mathrm{Re}_{\text {flow }}$. The experimental results reveal that, for the mixing system with the impeller A_2 and A_3, the values of heat transfer coefficients increase with $\mathrm{Re}_{\text {flow }}$. This indicates that the geometrical configuration of the impeller has

Table 2. The values of the parameters in Eq. (19)

\begin{tabular}{|c|c|c|c|}
\hline \multirow{2}{*}{ Impeller } & \multicolumn{2}{|c|}{ Eq. (19) } & \multicolumn{2}{c|}{$\begin{array}{c}\text { Coefficient } \\
\text { of determination } \\
R^{2}\end{array}$} \\
\cline { 2 - 4 } & $p_{1}$ & $p_{2}$ & 0.72 \\
\hline A_1 (Fig. 2a) & 35.47 & 0.14 & 0.34 \\
\hline A_2 (Fig. 2b) & 8.92 & 0.47 & 0.87 \\
\hline A_3 (Fig. 2c) & 3.29 & 0.95 \\
\hline
\end{tabular}

Table 3. The values of the parameters in Eq. (20)

\begin{tabular}{|c|c|c|c|c|}
\hline \multirow{2}{*}{ Impeller } & \multicolumn{2}{|c|}{ Eq. (20) } & \multicolumn{2}{c|}{$\begin{array}{c}\text { Coefficient } \\
\text { of determination } \\
R^{2}\end{array}$} \\
\cline { 2 - 5 } & $p_{3}$ & $p_{4}$ & 0.14 & 0.94 \\
\hline A_1 (Fig. 2a) & 32.33 & -0.02 & 0.09 & 0.79 \\
\hline A_2 (Fig. 2b) & 13.67 & 0.14 & 0.29 & 0.75 \\
\hline A_3 (Fig. 2c) & 4.08 & 0.06 & $p_{5}$ \\
\hline
\end{tabular}

Table 4. Main heat transfer effect connected with the application of the tested mixing systems

\begin{tabular}{|c|c|}
\hline $\begin{array}{l}\text { Configuration of the } \\
\text { tested impeller }\end{array}$ & Main heat transfer effects \\
\hline $\begin{array}{l}\text { A } 1 \text { (see Fig. 2a) } \\
\text { Results are presented in } \\
\text { Fig. 5a }\end{array}$ & $\begin{array}{l}\text { The maximum values of the heat transfer process are observed at lower } R_{\text {fow }}\left(\operatorname{Re}_{\text {flow }}<300\right) \text { and higher } \operatorname{Re}_{\text {mix }}\left(\operatorname{Re}_{\text {mix }}\right. \\
>25000) \text {. The values of the term } \mathrm{Nu} \mathrm{Pr}^{-0.33} \mathrm{Vi}^{-0.14} \text { for this range is equal to about } 115 \text {. }\end{array}$ \\
\hline $\begin{array}{l}\text { A_2 (see Fig. } 2 b) \\
\text { Results are presented in } \\
\text { Fig. } 5 b\end{array}$ & $\begin{array}{l}\text { The maximum values of the heat transfer process are observed at higher } \operatorname{Re} \text { flow }\left(\operatorname{Re}_{\text {flow }}>600\right) \text { and higher } \operatorname{Re}_{\text {mix }} \\
\left(\operatorname{Re}_{\text {mix }}>40000\right) \text {. The values of the term Nu } \operatorname{Pr}^{-0.33} \mathrm{Vi}^{-0.14} \text { for this range is equal to about } 80 \text {. }\end{array}$ \\
\hline $\begin{array}{l}\text { A_3 (see Fig. 2c) } \\
\text { Results are presented in } \\
\text { Fig. } 5 \mathrm{c}\end{array}$ & $\begin{array}{l}\text { The maximum values of the heat transfer process are observed at higher } \operatorname{Re} \text { flow }\left(\operatorname{Re}_{\text {flow }}>600\right) \text { and higher } \operatorname{Re}_{\text {mix }} \\
\left(\operatorname{Re}_{\text {mix }}>30000\right) \text {. The values of the term Nu } \operatorname{Pr}^{-0.33} \mathrm{Vi}^{-0.14} \text { for this range is equal to about } 140 \text {. }\end{array}$ \\
\hline
\end{tabular}



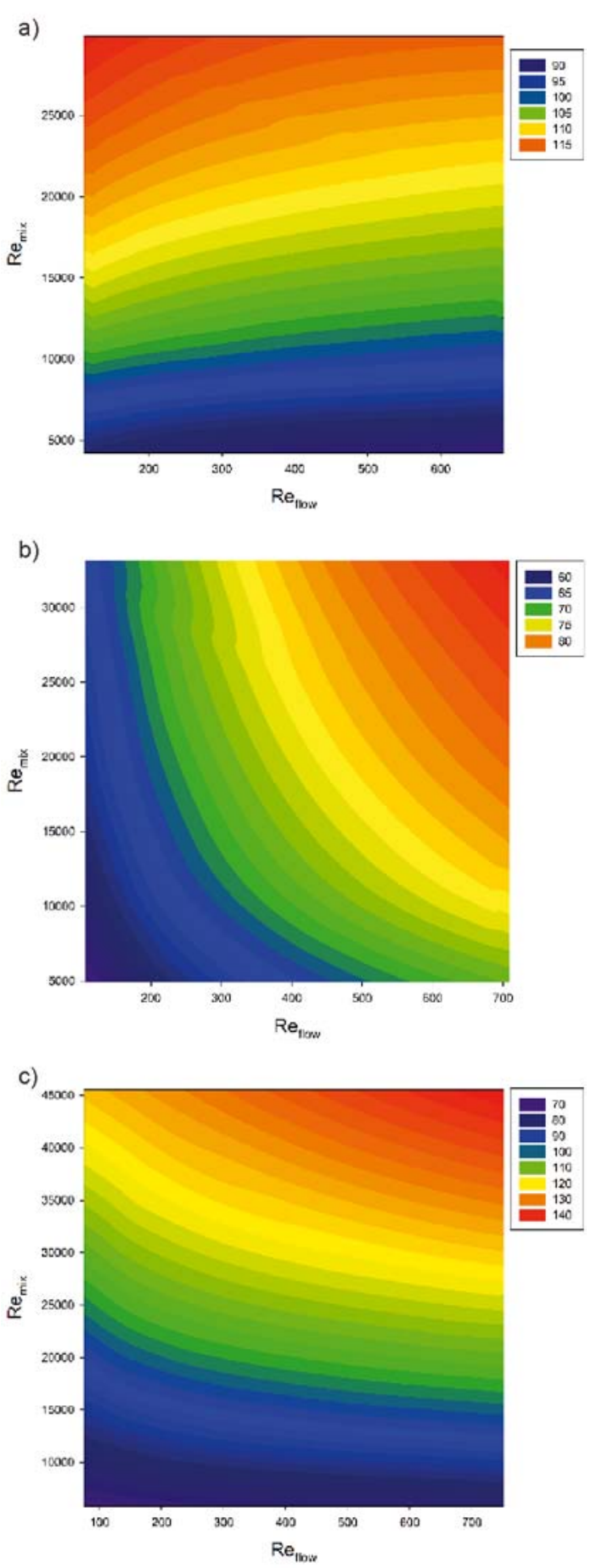

Figure 5. Contour plots for Eq. (20) for the mixing system with the configuration of the tested impeller A_1 (a), A_2 (b), and A_3 (c)

a significant effect on the tested process. From the analysis of Fig. 5, it follows that the synergic effect of the mixing process and the flowing liquid is also effective. It is observed that the heat transfer coefficient is highest for the configuration A_3 (see Fig. 2c).

\section{CONCLUSIONS}

This study sought to determine the heat transfer process for a mixing system equipped with the multi-ribbon impeller. The experimental results showed that the synergic effect of the mixing process and the flowing liquid provided higher values of the heat transfer coefficients. This parameter increased along with $\mathrm{Re}_{m i x}$ and with $\mathrm{Re}_{\text {flow }}$ (for impeller configurations of A_2 and
A_3). In the case of impeller configuration A_1, this parameter decreased along with $\operatorname{Re}_{\text {flow }}$ and increase along with $\mathrm{Re}_{m i x}$. Experiments related that the term $\mathrm{Nu}$ $\operatorname{Pr}^{-0.33} \mathrm{Vi}^{-0.14}$ in the system with the mixed liquid using the impeller is higher than the values obtained in the mixing system with the motionless impellers.

\section{ACKNOWLEDGMENTS}

The authors are grateful for the financial support of the National Centre for Research and Development within the POWER Program (Grant No POWR.03.05.00$-00-\mathrm{Z} 205 / 17)$. The obtained research was carried out in the Fabrication Laboratory (Fab-LAB) supported by the National Centre for Research and Development.

On behalf of all authors, the corresponding author states that there is no conflict of interest.

\section{LITERATURE CITED}

1. Henzler, H.J. \& Obernosterer, G. (1991). Effect of mixing behavior on gas-liquid mass transfer in highly viscous, stirred non-newtonian liquids. Chem. Eng. Technol. 14, 1-10. DOI: 10.1002/ceat.270140102.

2. Espinosa-Solares, T., Brito-De La Fuente, E., Tecante, A. \& Tanguy, P.A. (1997). Power consumption of a dual turbine-helical ribbon impeller mixer in ungassed conditions. Chem. Eng. J. 67, 215-219. DOI: 10.1016/S1385-8947(97)00040-5.

3. Cheng, J. \& Carreau, P.J. (1994). Aerated mixing of viscoelastic fluids with helical ribbons impellers. Chem. Eng. Sci. 49, 1965-1972. DOI: 10.1016/0009-2509(94)80080-4.

4. Cheng, J. \& Carreau, P.J. (1994). Mixing in the transition flow regime with helical ribbon agitators. Can. J. Chem. Eng. 72, 418-430. DOI: 10.1002/cjce.5450720306.

5. Brito-De La Fuente, E., Nuñez, M.C. \& Tanguy, P.A. (1997). Non-isothermal of rheologically complex fluids with close-clearance impellers: Effect of natural convection. Chem. Eng. Technol. 20, 203-207. DOI: 10.1002/ceat.270200308.

6. Shamlou, P.A. \& Edwards, M.F. (1985). Power consumption of helical ribbon mixers in viscous Newtonian and non-Newtonian fluids. Chem. Eng. Sci. 40, 1773-1781. DOI: 10.1016/0009-2509(85)80040-3.

7. Carreau, P.J., Chhabra, J. \& Cheng, J. (1993). Effect of rheological properties on power consumption with helical ribbon agitators. AIChE J 39,1421-1430. DOI: 10.1002/aic.690390902.

8. Masiuk, S., Łącki, H. \& Stręk, F. (1992). Power consumption and mixing times for liquid mixing in a ribbon mixer. Chem. Eng. J. 48, 135-130. DOI: 10.1016/0300-9467(92)85015-2.

9. Masiuk, S. \& Łącki, H. (1993). Power consumption and mixing time for Newtonian and non-Newtonian liquids mixing in a ribbon mixer. Chem. Eng. J. 48, 13-17. DOI: 10.1016/03009467(93)80037-O.

10. Masiuk, S. (1993). Power consumption, mixing time and attrition action for solid mixing in a ribbon mixer. Powder Technol. 51, 217-229. DOI: 10.1016/0032-5910(87)80022-0.

11. Kaneko, Y., Shiojima, T. \& Horio, M. (2000). Numerical analysis of particle mixing characteristics in a single helical ribbon agitator using DEM simulation. Powder Technol. 108, 55-64. DOI: 10.1016/S0032-5910(99)00251-X.

12. Zhang, M., Zhang, L., Jiang, B., Yin, Y. \& Li, X. (2008). Calculation of Metzner constant for double helical ribbon impeller by computational fluid dynamic method. Chin. J. Chem. Eng. 16(5), 686-692. DOI: 10.1016/S1004-9541(08)60141-X.

13. Nagata, S., Nishikawa, M., Kayama, T. \& Nakajima, M. (1972). Heat transfer to cooling coil acting as rotating coil-type impeller in highly viscous liquids. Chem. Eng. Jpn 5, 187-192. DOI: $10.1252 /$ jcej.5.187.

14. Shamlou, P.A. \& Edwards, M.F. (1986). Heat transfer to viscous Newtonian and non-Newtonian fluids for helical ribbon 
mixers. Chem. Eng. Sci. 41, 1957-1967. DOI: 10.1016/00092509(86)87112-3.

15. Mitsuishi, N. \& Miyairi, Y. (1973). Heat transfer to non-newtonian fluids in an agitated vessel. J. Chem. Eng. Jpn $6,415-420$.

16. Ishibashi, K., Yamanaka, A. \& Mitsuishi, N. (1979). Heat transfer in agitated vessels with special types of impellers. $J$. Chem. Eng. Jpn 12, 230-236. DOI: 10.1252/jcej.12.230.

17. Lehrer, I.H. (1970). Jacket-side Nusselt number. Ind. Eng. Chem. Proc. Des Dev 9, 553-558. DOI: 10.1021/i260036a010.

18. Nagata, S. (1975). Mixing: Principles and Applications. New York, USA: Wiley.

19. Delaplace, G., Demeyre, J.-F., Guérin, R., Debreyne, P. \& Leuliet, J.-C. (2005). Determination of representative and instaneous process side heat transfer coefficients in agitated vessel using heat flux sensors. Chem. Eng. Proc. Process Intensific. 44(9), 993-998. DOI: 10.1016/j.cep.2004.11.005.

20. Niedzielska, A. \& Kuncewicz, C. (2005). Heat transfer and power consumption for ribbon impellers. Mixing efficiency. Chem. Eng. Sci. 60, 2439-2448. DOI: 10.1016/j.ces.2004.10.046.

21. Nzihou, A., Bournoville, B., Marchal, P. \& Choplin, L. (2004). Rheology and heat transfer during mineral residue phosphatation in a rheo-reactor. Chem. Eng. Res. Design 82, 637-641. DOI: 10.1205/026387604323142694.

22. Delaplace, G., Torrez, C., Leuliet, J.-C., Belaubre, N. \& Andre, C. (2001). Experimental and CFD simulation of heat transfer to highly viscous fluids in an agitated vessel equipped with a non standard helical ribbon impeller. Chem. Eng. Res. Des. 79(8), 927-937. DOI: 10.1205/02638760152721460.

23. Rai, C.L., Devotta, I. \& Rao, P.G. (2000). Heat transfer to viscous Newtonian and non-Newtonian fluids using helical ribbon agitator. Chem. Eng. J. 79, 73-77. DOI: 10.1016/S13858947(00)00169-8.

24. Saraceno, L., Boccardi, G., Celata, G.P., Lazzarini, R. \& Trinchieri, R. (2011). Development of two heat transfer correlations for a scraped surface heat exchanger in an ice-cream machine. Appl. Thermal Eng. 31, 17-18. DOI: 10.1016/j. applthermaleng.2011.08.022.

25. Gammoudi, A., Ayadi, A. \& Baccar, M. (2016). The hydrodynamic and thermal characterization of a yield stress fluid in stirred tanks equipped with simple helical ribbons with two stages. Meccanica 52, 1733-1736. DOI: 10.1007/ s11012-016-0506-z.

26. Karcz, J. (1999). Studies of local heat transfer in a gas-liquid system agitated by double disc turbines in a slender vessel. Chem. Eng. J. 72, 217-227. DOI: 10.1016/S13858947(99)00005-4.

27. Rakoczy, R., Masiuk, M., Kordas, M. \& Grądzik, P. (2011) The effects of power characteristics on the heat transfer process in various types of motionless mixing devices. Chem. Eng. Proc. 50, 959-969. DOI: 10.1016/j.cep.2011.07.001. 